\title{
Developmental norms for eight instruments used in the neuropsychological assessment of children: studies in Brazil
}

\footnotetext{
G.N.O. Brito ${ }^{1,2}$,

G.M.N. Alfradique ${ }^{1,2}$,

C.C.S. Pereira ${ }^{1,2}$,

C.M.B. Porto ${ }^{2}$ and

T.R. Santos ${ }^{1,2}$
}

\author{
${ }^{1}$ Laboratório de Neuropsicologia Clínica, Setor de Neurociências, \\ Departamento de Pediatria, Instituto Fernandes Figueira, FIOCRUZ, \\ Rio de Janeiro, RJ, Brasil \\ ²Laboratório de Neuropsicologia Clínica, Setor de Neurociências, \\ Universidade Federal Fluminense, Niterói, RJ, Brasil
}

\begin{abstract}
Correspondence
G.N.O. Brito

Caixa Postal 100846

24001-970 Niterói, RJ

Brasil

Fax: 55 (021) 620-5266

E-mail:ccsgnob@vm.uff.br

Presented in part at the II Brazilian Congress of Neuropsychology, Campinas, SP, Brasil, May 18-20, 1995.

Research supported by CNPq (No. 52.1025/94-0), PIBIC/CNPq/ FIOCRUZ, PAPES/FIOCRUZ and FUNPENE. G.M.N. Alfradique, C.C.S. Pereira and T.R. Santos are recipients of PAP/FIOCRUZ fellowships.
\end{abstract}

Received May 23, 1997 Accepted November 25, 1997

\section{Abstract}

Norms for a battery of instruments, including Denckla's and Garfield's tests of Motor Persistence, Benton's Right-Left Discrimination, two recall modalities (Immediate and Delayed) of the Bender Test, Wechsler's Digit Span, the Color Span Test and the Human Figure Drawing Test, were developed for the neuropsychological assessment of children in the greater Rio de Janeiro area. Additionally, the behavior of each child was assessed with the Composite Teacher Rating Scale (Brito GNO and Pinto RCA (1991) Journal of Clinical and Experimental Neuropsychology, 13: 417-418). A total of 398 children (199 boys and 199 girls balanced for age) with a mean age of 9.3 years $(\mathrm{SD}=2.8)$, who were attending a public school in Niterói, were the subjects of this study. Gender and age had significant effects on performance which depended on the instrument. Nonachievers performed worse than achievers in most neuropsychological tests. Comparison of our data to the available counterparts in the United States revealed that American children outperformed Brazilian children on the Right-Left Discrimination, Forward Digit Span, Color Span and Human Figure Drawing Tests. Further analysis showed that the neurobehavioral data consist of different factorial dimensions, including Human Body Representation, Motor Persistence of the Legs, Orbito-Orobuccal Motor Persistence, Attention-Memory, Visuospatial Memory, Neuropsychomotor Speed, Hyperactivity-Inattention, and Anxiety-Negative Socialization. We conclude that gender and age should be taken into account when using the normative data for most of the instruments studied in the present report. Furthermore, we stress the need for major changes in the Brazilian public school system in order to foster the development of secondary cognitive abilities in our children.
Key words

- Neuropsychology

- Assessment instruments

- Norms

- Development

- Cross-cultural differences

- Brazil 


\section{Introduction}

Studies of child neuropsychology in Brazil are hampered by the lack of adequate normative information on the performance of instruments used in neuropsychological assessment. Perusal of a major book on psychological tests published in this country (1) clearly indicates the magnitude of the problem since norms derived in Brazil are available for only a few instruments. Furthermore, in most cases, lack of critical information about the sample and statistical procedures renders the norms inadequate. As an example, a large-scale study (2) on the Bender test conducted in Porto Alegre (RS, Brazil) and included in a book published by Cunha (1) did not provide sufficient information on the demographic aspects of the sample and used crude statistical procedures. In contrast, the normative study of Hutz and Antoniazzi (3) on human figure drawing, also conducted in Porto Alegre (RS, Brazil), was well designed and used powerful statistical techniques. Furthermore, the latter authors were careful to describe the demographic aspects of their rather large sample $(\mathrm{N}=1856$ children $)$. The report of Hutz and Antoniazzi (3) certainly is an exception in comparison to most normative studies that have been performed in Brazil (see Ref. 1) from the standpoint of methodology and data analysis. The need for adequate locally derived normative data has been emphasized by other investigators (e.g., 4), but continues to plague neuropsychological research in Brazil.

In the present study, we provide local "developmental norms" for several instruments used in the neuropsychological assessment of children as part of a neuropsychological battery. This battery comprised Denckla's (5) and Garfield's (6) Tests of Motor Persistence, Right-Left Discrimination (4), Wechsler Intelligence Scale for Children-Revised (WISC-R)'s Forward and Backward Digit Span (7), the Color Span Test (8) and the Human Figure Drawing (9). Additionally, we added two versions to the stan- dard and stress administrations of the Bender Test in order to assess visual attention and memory, the Immediate and Delayed Recall modalities. Furthermore, each child in the study underwent behavioral assessment with the Composite Teacher Rating Scale (ComTRS) (10). Moreover, the underlying dimensional structure of the neuropsychological and behavioral data was examined by factor analysis.

The instruments described above were selected for inclusion in the battery on the basis of data indicating that the developmentally disabled child frequently demonstrates impairment in the performance of these tests, as reviewed by Gardner (11) with respect to Denckla's (5) and Garfield's (6) Tests of Motor Persistence, Benton's Right-Left Discrimination Test (4), WISC-R's Forward and Backward Digit Span (7) and the Human Figure Drawing Test (9). Denckla et al. (12) showed that anomalies of motor development, including motor persistence, represent correlative markers of the attentional and behavioral status of children. Richman et al. (13-15) showed that reading-disabled children had difficulty with verbal, visual and intermodal memory, as measured by the Color Span Test, which depended on age. Furthermore, these authors demonstrated that three different subgroups of learning-disabled children (language disorder, visuoperceptual disorder and memory disorder) had specific memory profiles in the Color Span Test, and clear verbal and visual factors could be extracted from the factor analysis of the data.

The normative research presented in this paper is part of an ongoing program to develop instruments for the neurobehavioral assessment of children and adults in Brazil. Previous studies in this series have been published elsewhere (10,16-22).

\section{Material and Methods}

\section{Subjects}

A computer-generated random sample of 
398 children balanced for gender and age, described in detail elsewhere (22), was the subject of this study. Briefly, the children (199 boys and 199 girls) had a mean age of 9.3 years (standard deviation $=2.8$ ) and were attending a public school in the greater Rio de Janeiro area. This school was selected for the study because it attracts children from all ethnic groups and social strata as shown by the racial and paternal occupation distribution of children in the sample (for details, see Ref. 22). Additionally, as described previously (21), the proportion of girls in the school increases with age due to a substantial dropout rate for boys, which is a common observation in the Brazilian public school system. Sixty-four (16\%) children had failed at least one grade in school. The sample included 37 (9.3\%) children who preferred to write with the left hand and 361 $(90.7 \%)$ who preferred to write with the right hand, a frequency distribution consistent with data reported elsewhere (20). Therefore, it is presumed that the sample is representative of the population of public school children in the greater Rio de Janeiro area. Twentyeight $(7 \%)$ children in need of neurological, psychological or speech therapy, according to their teachers, were nevertheless included in the normative sample.

\section{Behavioral assessment}

The teachers of the children were requested to complete the Composite Teacher Rating Scale (10). Briefly, the teachers were required to have known the children for at least two months before completing the scale. Furthermore, they were instructed to respond to the items as briefly as possible and to rate each child by comparing his or her behavior with that of an "average" child of the same gender and age as the child being rated. The ComTRS was scored from not at all (0) and just a little (1) to pretty much (2) and very much (3). The ComTRS consists of 71 items distributed among five factorial dimensions
(Hyperactivity-Conduct Problem; Independent Functioning-Positive Socialization; Inattention; Anxiety; Negative Socialization). Scores for each of these factors were computed for each child and used as indices of behavioral assessment in the statistical analysis of the data.

\section{Neuropsychological battery}

The neuropsychological battery used in the present study was administered over two sessions (one session a day) and comprised the tests listed below in the order administered. Children were tested individually in a quiet room in the school. The examiners were one recent graduate in psychology and three recent graduates in speech therapy, who were trained in the administration and scoring of each test of the battery in a pilot study conducted before this study began. As reported previously for the normal and stress modalities of the Bender Test (22), there was no statistical effect due to examiner.

The first session consisted of the following tests:

1. Bender Test: Normal and Stress (data reported in Ref. 22), and Immediate Recall modalities. The procedures for the administration of the normal and stress modalities were as described by Lezak (23). Immediately after the administration of the stress modality, the cards were removed, the child was given a blank sheet of paper and requested to draw all the figures he or she could recall, not necessarily in the order of presentation. Scoring procedures were as reported by Koppitz (24). Furthermore, an omitted figure received a score equivalent to the maximum number of errors allowed for it, according to the scoring procedures. After completion of this modality, the child was requested to report how many figures he or she thought were missing and could not be recalled. Time to complete the task was recorded with a stopwatch.

2. Balancing on One Foot: Procedures 
for this test were reported by Denckla (5). Briefly, the length of time that each child could stand on one leg was measured with a stopwatch for a maximum of $30 \mathrm{~s}$ for each leg.

3. Garfield's Tests: Only the four tests found to be most useful by Gardner (11) were administered according to procedures described by Garfield (6). The examiner measured the length of time (maximum of 20 s) each child was capable of persisting in the performance of the following tasks: i) keeping the eyes closed, ii) protruding tongue with eyes closed, iii) protruding tongue with eyes open, and iv) keeping the mouth open. Two trials were administered for each task.

4. Right-Left Discrimination: Procedures for this test were reported by Benton (4). Briefly, the child was requested to perform 20 commands referring to his/her right or left side and the right or left side of a confronting person (i.e., the examiner) with open eyes. The number of commands performed correctly was recorded.

5. Bender Test: Delayed Recall modality. Immediately after the Right-Left Discrimination Test, the child was again requested to draw all the figures of the Bender Test he (or she) could recall without considering the order of presentation, and to give the number of figures which were missing and could not be recalled. Administration and scoring procedures were as described above for the Immediate Recall Bender. The mean time interval between the end of the Immediate Recall modality and the beginning of the Delayed Recall modality was 16.77 min (standard deviation $=3.03$ ). The time to complete the task was recorded with a stopwatch.

The second session included the following tests:

6. Digit Span Test (Forward and Backward) of the WISC-R: Procedures for the administration and scoring of this test were as described by Wechsler (7).

7. Color Span Test: Briefly, the Color Span Test consists of four subtests charac- terized by different stimulus and response combinations: Visual presentation-Visual response (Visual-Visual); Visual presentation-Verbal response (Visual-Verbal); Verbal presentation-Visual response (VerbalVisual), and Verbal presentation-Verbal response (Verbal-Verbal). Three cards with eight colors arranged in different spatial positions on each were used in this test. The examiner presented the child (visually or verbally) with color sequences of increasing length and the child was required to show retention of the sequences either by pointing (Visual mode) or orally (Verbal mode). Details of the administration and scoring procedures were as reported by Richman (8).

8. Human Figure Drawing Test: Procedures for the administration and scoring of this test were as described by Harris (9). Briefly, the child was requested to draw the whole figure (not only the head and shoulders) of a man, a woman and his or her own, one at a time, on separate sheets of paper.

\section{Statistics}

Statistical procedures available in the Statistical Analysis System package (25) were used for data analysis. Briefly, the data were initially subjected to multivariate analysis of variance (MANOVA) to provide control for the experimentwise error rate. The neuropsychological battery was divided into three groups of tests for the purpose of MANOVA: i) motor persistence (Denckla's Balancing on One Foot and Garfield's Tests) and RightLeft discrimination; ii) attention and memory: Immediate and Delayed Recall of the Bender Test, WISC-R's Digit Span, and the four subtests (Visual-Visual, Visual-Verbal, Verbal-Visual and Verbal-Verbal) of the Color Span Test, and iii) drawing of a man, woman and own figure. Significant MANOVAs were followed up with univariate ANOVAs for each dependent variable. If the ANOVAs were significant, post hoc Scheffé's tests were performed. In addition, the performance 
of Brazilian children was compared to that of children from the United States by bilateral $t$-tests across gender and age groups with (and without) Bonferroni correction for error rates.

The data about the Motor Persistence and Right-Left Discrimination Tests, and the Attention and Memory Tests, were further subjected to separate principal components factor analysis with orthogonal rotation and the varimax criterion. However, it was deemed important to include an index of cognitive performance (i.e., the Human Figure Drawing Test (9), but see 26) and the factor scores derived from the ComTRS (10) in the factor analysis of each group of variables so that it could be determined how neuropsychological variables cluster with cognitive and pure behavioral variables. Only factors with eigenvalues greater than unity were retained in the analysis and a criterion of at least 0.40 to define a loading was used in the present report. Since the main objective of the present study was to explore the underlying dimensions of the neuropsychological data, items with significant loadings on more than one factor were retained and explained. Data for children with values missing were excluded from factor analysis.

\section{Results}

MANOVAs of data concerning ethnic group, hand preference, paternal occupation and need for treatment had no significant effect on any of the neuropsychological variables used in data analysis. Therefore, no further mention of these demographic variables will be made in the presentation of the results.

\section{Motor Persistence and Right-Left Discrimination Tests}

A MANOVA of the data for the performance in the Motor Persistence (Denckla's and Garfield's Tests) and the Right-Left Dis- crimination Tests revealed significant effects of age, but not of gender $(\mathrm{F}=3.79, \mathrm{P}=$ 0.0001). Post hoc analysis of the data demonstrated that the older the child the better the performance on Denckla's Balancing on One Foot and Benton's Right-Left Discrimination Tests. There was no effect of age on the performance in Garfield's tests, i.e., performance was already at ceiling level at the earliest age (5.0-5.5) examined in the present study.

Covariate analysis of variance with age as the covariate demonstrated that nonachievers had significantly lower total scores in the Right-Left Discrimination Test than achievers $(\mathrm{F}=4.69, \mathrm{P}=0.03)$. There were no statistically significant differences in performance between groups of children for the tests of motor persistence.

Table 1 shows the performance on the Denckla's Test of Balancing on One Foot across age and Table 2 summarizes the ages

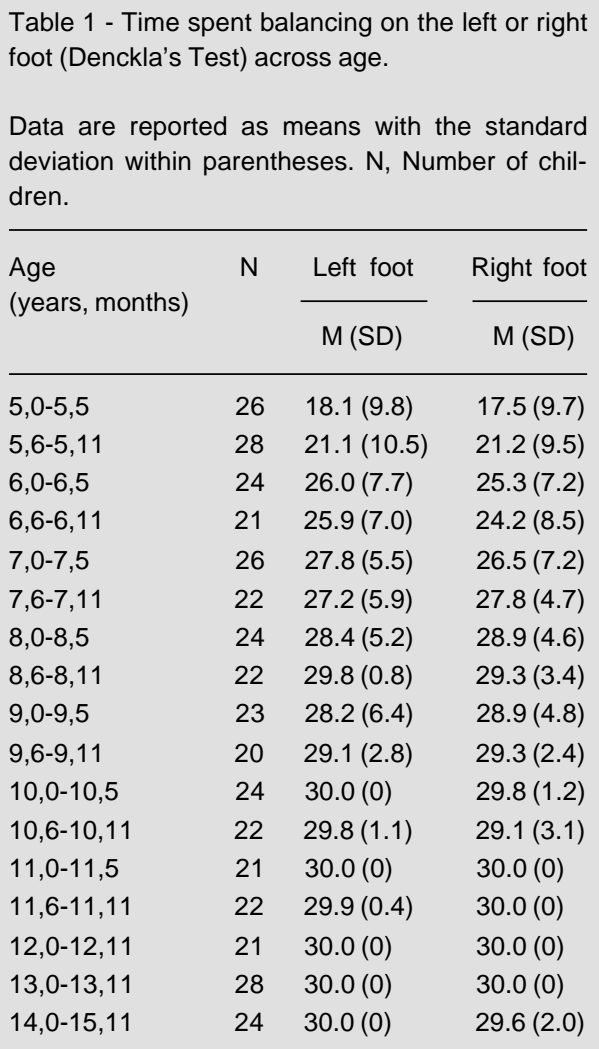


at which children should perform the different tasks included in the Right-Left Discrimination Test. The normative data for Garfield's tests are not shown because no effect of gender or age was found, i.e., children of both sexes performed at ceiling levels (40 s over two trials for each task) from the earliest age examined.

Comparison of our data with the data reported by Denckla (5) revealed that there were no major differences in the performance of the test of Balancing on One Foot between Brazilian and American children. Additionally, our results are equivalent to those reported by Garfield (6) for U.S. children in the age range that he examined. However, we found that Brazilian children show a delay in the attainment of the identification of single lateral parts of their own body and in executing uncrossed commands in comparison to North American children (4), but they later catch up, so that by age eleven their performance becomes indistinguishable from that of U.S. children.

Table 2 - Ages at which children should perform the tasks of the Right-Left Discrimination Test.

\begin{tabular}{lc}
\hline Task & Age \\
\hline 1. Show me your left hand & $7-8$ \\
2. Show me your right eye & $7-8$ \\
3. Show me your left ear & $7-8$ \\
4. Show me your right hand & $7-8$ \\
& \\
5. Touch your left ear with your left hand & 9 \\
6. Touch your right knee with your right hand & 9 \\
7. Touch your left eye with your left hand & 9 \\
8. Touch your right ear with your right hand & 9 \\
9. Touch your right eye with your left hand & 10 \\
10. Touch your right ear with your left hand & 10 \\
11. Touch your left knee with your right hand & 10 \\
12. Touch your left eye with your right hand & 10 \\
13. Point to my right eye & 11 \\
14. Point to my left leg & 11 \\
15. Point to my left ear & 11 \\
16. Point to my right hand & 11 \\
17. Put your right hand on my left ear & 13 \\
18. Put your left hand on my left eye & 13 \\
19. Put your left hand on my right shoulder & 13 \\
20. Put your right hand on my right eye & 13
\end{tabular}

\section{Attention and Memory Tests}

The normative results for the performance of the Immediate and Delayed Recall Bender Test, WISC-R's Digit Span subtest and the Color Span Test are shown in Tables 3, 4 and 5 , respectively.

MANOVA performed on the data revealed significant $\operatorname{sex}(\mathrm{F}=2.81, \mathrm{P}=0.005)$ and age $(\mathrm{F}=5.43, \mathrm{P}=0.0001)$ effects. ANOVA on error scores on the Immediate and Delayed Recall Bender indicated significant gender and age effects. However, there were no sex or age effects on time to complete either modality. Post hoc analysis of the data revealed that girls outperformed boys and older children outperformed younger children in both modalities of the Recall Bender.

Further analysis of the data demonstrated a significant effect of age, but not of gender, on the performance of the Forward and Backward sections of the Digit Span Test such that the older the child the better the performance. Moreover, age had a significant effect on the performance of each subtest of the Color Span Test, but sex had an effect only on the performance of the Visual-Visual and Verbal-Visual subtests. Post hoc analysis of the data revealed that older children performed each modality better than younger children. Additionally, girls outperformed boys in the Visual-Visual subtest. However, the post hoc Scheffé test for gender comparison in the performance of the Verbal-Visual modality was nonsignificant.

Covariate analysis of variance with age as the covariate revealed that nonachievers made significantly more errors in the Immediate $(\mathrm{F}=3.75, \mathrm{P}=0.05)$ and Delayed $(\mathrm{F}=3.66, \mathrm{P}=0.05)$ Recall Bender Tests than achievers. There were no differences between groups in the time to complete the Bender Tests. Additionally, nonachievers performed worse than achievers in the Backward, but not Forward, section of the Digit Span Test $(\mathrm{F}=4.69, \mathrm{P}=0.03)$, and each 
subtest of the Color Span Test (Visual-Visual: $\mathrm{F}=11.61, \mathrm{P}=0.0007$; Visual-Verbal: $\mathrm{F}$ $=8.42, \mathrm{P}=0.003 ;$ Verbal-Visual: $\mathrm{F}=5.23, \mathrm{P}$ $=0.02$; Verbal-Verbal: $\mathrm{F}=6.19, \mathrm{P}=0.01$ ).

Multiple bilateral $t$-test comparisons of our data on the performance of the Digit Span Test (Forward and Backward) to those reported for U.S. children (11) revealed that U.S. children outperformed Brazilian children in the Forward Digit Span across both genders and all ages, except for the 14 year and older groups. Comparison of the perfor- mance of U.S. and Brazilian children in the Backward modality of the Digit Span demonstrated that U.S. children performed better than Brazilian children irrespective of gender in some, but not all, age groups. Bonferroni's correction for the alpha level of significance obliterated most of the statistical differences found for the Backward modality and several of the differences found for the Forward modality (Brazilian-U.S. children comparison data are available from the senior author).

\begin{tabular}{|c|c|c|c|c|c|}
\hline \multirow{2}{*}{$\begin{array}{l}\text { Age } \\
\text { (years, months) }\end{array}$} & & \multicolumn{2}{|c|}{ Immediate Memory } & \multicolumn{2}{|c|}{ Delayed Memory } \\
\hline & & Male & Female & Male & Female \\
\hline \multirow{2}{*}{$5,0-5,5$} & $M(S D)$ & $23.1(4.5)$ & $21.8(3.8)$ & $22.9(4.7)$ & $21.7(4.0)$ \\
\hline & $\mathrm{N}$ & 14 & 12 & 14 & 12 \\
\hline \multirow[t]{2}{*}{$5,6-5,11$} & $M(S D)$ & $22.5(3.6)$ & $18.2(3.9)$ & $22.3(3.6)$ & $18.1(4.0)$ \\
\hline & $\mathrm{N}$ & 13 & 15 & 13 & 15 \\
\hline \multirow[t]{2}{*}{$6,0-6,5$} & $M(S D)$ & $20.8(4.1)$ & $18.5(3.5)$ & $20.8(4.1)$ & $18.5(3.5)$ \\
\hline & $\mathrm{N}$ & 12 & 12 & 12 & 12 \\
\hline \multirow[t]{2}{*}{$6,6-6,11$} & $M(S D)$ & $18.8(3.7)$ & $18.0(3.7)$ & $18.7(3.7)$ & $18.0(3.7)$ \\
\hline & $N$ & 10 & 11 & 10 & 11 \\
\hline \multirow[t]{2}{*}{$7,0-7,5$} & $M(S D)$ & $16.5(5.6)$ & $14.8(4.1)$ & $16.5(5.6)$ & $14.7(4.2)$ \\
\hline & $N$ & 13 & 13 & 13 & 13 \\
\hline \multirow[t]{2}{*}{$7,6-7,11$} & $M(S D)$ & $17.6(4.5)$ & $15.0(3.4)$ & $17.5(4.6)$ & $14.9(3.3)$ \\
\hline & $\mathrm{N}$ & 11 & 11 & 11 & 11 \\
\hline \multirow[t]{2}{*}{$8,0-8,5$} & $M(S D)$ & 16.5 (3.3) & $12.5(4.5)$ & $16.5(3.3)$ & $12.5(4.5)$ \\
\hline & $\mathrm{N}$ & 13 & 11 & 13 & 11 \\
\hline \multirow[t]{2}{*}{$8,6-8,11$} & $M(S D)$ & $15.6(4.7)$ & $11.2(3.4)$ & $15.6(4.7)$ & $11.2(3.4)$ \\
\hline & $\mathrm{N}$ & 11 & 11 & 11 & 11 \\
\hline \multirow[t]{2}{*}{$9,0-9,5$} & $M(S D)$ & $13.1(6.1)$ & $13.1(3.0)$ & $13.1(6.1)$ & 13.0 (3.3) \\
\hline & $\mathrm{N}$ & 12 & 11 & 12 & 11 \\
\hline \multirow[t]{2}{*}{$9,6-9,11$} & $M(S D)$ & $10.1(4.5)$ & $11.7(4.5)$ & $10.1(4.5)$ & $11.7(4.5)$ \\
\hline & $\mathrm{N}$ & 10 & 10 & 10 & 10 \\
\hline \multirow[t]{2}{*}{$10,0-10,5$} & $M(S D)$ & $13.3(3.6)$ & $11.8(3.6)$ & $13.3(3.6)$ & $11.8(3.8)$ \\
\hline & $\mathrm{N}$ & 11 & 13 & 11 & 13 \\
\hline \multirow[t]{2}{*}{$10,6-10,11$} & $M(S D)$ & $13.0(3.1)$ & $10.7(4.3)$ & $13.0(3.1)$ & $10.6(4.3)$ \\
\hline & $N$ & 11 & 11 & 11 & 11 \\
\hline \multirow[t]{2}{*}{$11,0-11,5$} & $M(S D)$ & $10.3(4.1)$ & $10.5(3.6)$ & $10.3(4.1)$ & $10.5(3.6)$ \\
\hline & $\mathrm{N}$ & 11 & 10 & 11 & 10 \\
\hline \multirow[t]{2}{*}{$11,6-11,11$} & $M(S D)$ & $11.8(6.1)$ & $7.8(4.6)$ & $11.8(6.1)$ & $7.8(4.6)$ \\
\hline & $N$ & 11 & 11 & 11 & 11 \\
\hline \multirow[t]{2}{*}{$12,0-12,11$} & $M(S D)$ & $10.2(4.1)$ & $8.5(4.2)$ & $10.2(4.1)$ & $8.5(4.2)$ \\
\hline & $\mathrm{N}$ & 10 & 11 & 10 & 11 \\
\hline \multirow[t]{2}{*}{$13,0-13,11$} & $M(S D)$ & $7.4(5.0)$ & $6.8(4.0)$ & $7.4(5.0)$ & $6.8(4.0)$ \\
\hline & $\mathrm{N}$ & 15 & 13 & 15 & 13 \\
\hline \multirow{2}{*}{$14,0-15,11$} & $M(S D)$ & $8.1(4.3)$ & $7.8(4.0)$ & $8.0(4.1)$ & $7.7(4.1)$ \\
\hline & $N$ & 11 & 13 & 11 & 13 \\
\hline
\end{tabular}


Multiple $t$-tests of the differences in performance in the modalities of the Color Span Test for U.S. and Brazilian children across gender and age demonstrated significant differences in performance between the two groups of children for each modality, especially the Visual-Visual modality. Bonferroni's correction for the alpha level of significance did not alter the pattern of these differences in a major way (BrazilianUS children comparison data are available from the senior author).

\section{Human Figure Drawing Test}

The normative data for the performance of the Human Figure Drawing Test for boys and girls across age are presented in Table 6 . MANOVA revealed significant differences for gender $(\mathrm{F}=12.71, \mathrm{P}=0.0001)$ and age $(\mathrm{F}$ $=9.26, \mathrm{P}=0.0001)$ in the drawing performance of a man and a woman, and signifi-

Table 4 - Scores for WISC-R Digit Span subtest across age.

Data are reported as means with the standard deviation within parentheses. $\mathrm{N}$, Number of children.

\begin{tabular}{|c|c|c|c|}
\hline \multirow{2}{*}{$\begin{array}{l}\text { Age } \\
\text { (years, months) }\end{array}$} & \multirow[t]{2}{*}{$\mathrm{N}$} & \multirow{2}{*}{$\frac{\text { Forward }}{\mathrm{M}(\mathrm{SD})}$} & \multirow{2}{*}{$\frac{\text { Backward }}{M(S D)}$} \\
\hline & & & \\
\hline $5,0-5,5$ & 25 & $1.5(1.4)$ & $0.2(0.6)$ \\
\hline $5,6-5,11$ & 28 & $2.2(1.1)$ & $0.4(1.0)$ \\
\hline $6,0-6,5$ & 23 & $2.4(1.8)$ & $0.9(1.3)$ \\
\hline $6,6-6,11$ & 21 & $3.2(1.6)$ & $1.6(1.8)$ \\
\hline $7,0-7,5$ & 26 & $3.5(1.2)$ & $2.3(1.4)$ \\
\hline $7,6-7,11$ & 21 & $3.8(1.3)$ & $2.6(1.4)$ \\
\hline $8,0-8,5$ & 24 & $4.1(1.2)$ & $3.4(1.3)$ \\
\hline $8,6-8,11$ & 22 & $4.0(1.1)$ & $3.6(1.5)$ \\
\hline $9,0-9,5$ & 23 & $4.4(1.3)$ & $2.9(1.3)$ \\
\hline $9,6-9,11$ & 20 & $4.1(1.4)$ & $3.4(1.2)$ \\
\hline $10,0-10,5$ & 24 & $4.2(1.2)$ & $3.8(1.6)$ \\
\hline $10,6-10,11$ & 22 & $4.5(1.2)$ & $3.7(1.3)$ \\
\hline $11,0-11,5$ & 21 & $4.8(1.4)$ & $4.8(1.7)$ \\
\hline $11,6-11,11$ & 22 & $4.9(1.3)$ & $3.5(1.4)$ \\
\hline $12,0-12,11$ & 21 & $5.4(1.6)$ & $4.8(1.3)$ \\
\hline $13,0-13,11$ & 28 & $5.2(1.5)$ & $4.8(1.1)$ \\
\hline $14,0-15,11$ & 24 & $5.3(1.1)$ & $5.0(1.5)$ \\
\hline
\end{tabular}

cant differences for age $(\mathrm{F}=5.01, \mathrm{P}=0.0001)$ in the drawing of own figure. Boys drew the figures of a man $(F=4.26, P=0.039)$ and a woman $(F=19.27, P=0.0001)$ significantly worse than girls. Further analysis of the data revealed that the performance of children in the drawing of each of the three figures improved significantly with age. In addition, there were no significant differences in performance between the drawing of the figure of a man and oneself for boys, and between the drawing of the figure of a woman and oneself for girls.

Covariate analysis of variance with age as the covariate showed that nonachievers performed the Human Figure Drawing Test significantly worse than achievers (man: $\mathrm{F}=$ $6.65, \mathrm{P}=0.01$; woman: $\mathrm{F}=6.24, \mathrm{P}=0.01$; own figure drawn by boys: $\mathrm{F}=3.54, \mathrm{P}=$ 0.06 ; own figure drawn by girls: $\mathrm{F}=13.80, \mathrm{P}$ $=0.0003$ ).

Comparison of the results reported by Harris (9) with the present data indicated that Brazilian children performed the $\mathrm{Hu}-$ man Figure Drawing Test significantly worse than U.S. children across all ages, except for the 6-year-old group of girls drawing the man's figure. The use of Bonferroni's correction for the alpha level of significance would not change this conclusion in a significant way, since only the performance of 15-year-old Brazilian boys drawing the man's figure would become equivalent to that of their U.S. counterparts (Brazilian-U.S. children comparison data are available from the senior author).

\section{Factor analysis of the neuropsychological battery data}

Motor persistence and right-left discrimination. A principal components factor analysis of the data on the Denckla's and Garfield's Tests of Motor Persistence, the Right-Left Discrimination Test, Human Figure Drawing Test and the factor scores of the ComTRS (10) revealed five factors. The first 
factor ("Human Body Representation") extracted from this analysis included variables related to the performance of the $\mathrm{Hu}-$ man Figure Drawing Test and the Right-Left Discrimination Test. The second factor ("Hyperactivity-Inattention") consisted of the scores on the Hyperactivity-Conduct Problem, Independent Functioning-Positive Socialization and Inattention factors of the ComTRS (10). The third factor ("Motor Persistence of the Legs") included the variables derived from the Denckla test (balancing on the right and left foot). The fourth factor ("Anxiety-Negative Socialization") comprised the scores on the Anxiety and Negative Socialization factors of the ComTRS (10). The fifth factor ("Orbito-Orobuccal Motor Persistence") included the last three tasks of the Garfield Test (protruding the tongue with eyes closed; protruding the tongue with eyes open; keeping the mouth open).

Attention and memory. Five factors were extracted from the principal components analysis of the Attention and Memory Tests, the Human Figure Drawing Test and the factor scores of the ComTRS (10). The first factor ("Attention-Memory") included variables related to the performance of the Attention and Memory Tests (Digit Span, Color Span, error scores on the Immediate and Delayed Recall Bender). The second factor ("Visuospatial Memory") comprised variables related to the performance of the $\mathrm{Hu}$ man Figure Drawing and error scores in the Immediate and Delayed Recall Bender. Error scores in the Immediate and Delayed Recall Bender showed loadings evenly split on the first two factors. The scores on factors Hyperactivity-Conduct Problem, Independent Functioning-Positive Socialization and Inattention of the ComTRS (10) made up the third factor ("Hyperactivity-Inattention") extracted from the data. The fourth factor (“Anxiety-Negative Socialization") included the scores on the Anxiety and Negative So-

Table 5 - Scores for the different subtests of the Color Span Test across age.

Data are reported as means with the standard deviation within parentheses. N, Number of children.

\begin{tabular}{|c|c|c|c|c|c|c|c|c|}
\hline \multirow{2}{*}{$\begin{array}{l}\text { Age } \\
\text { (years, months) }\end{array}$} & \multicolumn{2}{|c|}{ Visual-Visual } & \multicolumn{2}{|c|}{ Visual-Verbal } & \multicolumn{2}{|c|}{ Verbal-Visual } & \multicolumn{2}{|c|}{ Verbal-Verbal } \\
\hline & $\mathrm{N}$ & $M(S D)$ & $\mathrm{N}$ & $M(S D)$ & $\mathrm{N}$ & $M(S D)$ & $\mathrm{N}$ & $M(S D)$ \\
\hline $5,0-5,5$ & 24 & $0.9(0.9)$ & 24 & $1.0(1.1)$ & 24 & $2.0(1.6)$ & 24 & $2.9(1.8)$ \\
\hline $5,6-5,11$ & 28 & $1.0(1.2)$ & 27 & $2.4(1.4)$ & 27 & $3.0(1.5)$ & 28 & $4.3(1.1)$ \\
\hline $6,0-6,5$ & 23 & $1.3(1.1)$ & 23 & $2.2(1.5)$ & 23 & $3.4(1.9)$ & 23 & $4.5(1.6)$ \\
\hline $6,6-6,11$ & 20 & $2.3(2.0)$ & 20 & $3.2(2.1)$ & 20 & $4.3(1.6)$ & 21 & $5.1(1.4)$ \\
\hline $7,0-7,5$ & 26 & $2.8(1.8)$ & 26 & $4.2(1.7)$ & 26 & $5.0(1.1)$ & 26 & $5.1(1.4)$ \\
\hline $7,6-7,11$ & 21 & $3.6(1.4)$ & 21 & $4.3(1.7)$ & 21 & $4.9(1.4)$ & 21 & $5.8(1.6)$ \\
\hline $8,0-8,5$ & 24 & $4.1(1.8)$ & 24 & $4.8(1.3)$ & 24 & $5.3(1.1)$ & 24 & $5.8(1.3)$ \\
\hline $8,6-8,11$ & 22 & $4.4(1.7)$ & 22 & $4.7(1.5)$ & 22 & $5.5(1.2)$ & 22 & $6.1(1.6)$ \\
\hline $9,0-9,5$ & 23 & $4.7(1.6)$ & 23 & $5.3(1.4)$ & 23 & $5.9(1.2)$ & 23 & $6.0(1.5)$ \\
\hline $9,6-9,11$ & 20 & $5.4(1.8)$ & 20 & $6.1(1.6)$ & 20 & $5.7(1.6)$ & 20 & $6.0(1.3)$ \\
\hline $10,0-10,5$ & 24 & $4.4(1.6)$ & 24 & $5.2(1.4)$ & 24 & $5.2(0.9)$ & 24 & $6.0(1.6)$ \\
\hline $10,6-10,11$ & 22 & $5.2(2.1)$ & 22 & $5.4(1.3)$ & 22 & $5.6(1.3)$ & 22 & $6.3(1.4)$ \\
\hline $11,0-11,5$ & 21 & $6.0(1.4)$ & 21 & $6.0(1.3)$ & 21 & $6.4(1.4)$ & 21 & $6.8(2.1)$ \\
\hline $11,6-11,11$ & 22 & $5.9(1.5)$ & 22 & $6.3(1.8)$ & 22 & $6.1(1.4)$ & 22 & $7.0(1.3)$ \\
\hline $12,0-12,11$ & 21 & $6.8(1.2)$ & 21 & $6.4(1.7)$ & 21 & $6.9(1.3)$ & 21 & $7.0(1.3)$ \\
\hline $13,0-13,11$ & 28 & $6.6(1.9)$ & 28 & $6.9(1.6)$ & 28 & $6.5(1.1)$ & 28 & $6.8(1.7)$ \\
\hline $14,0-15,11$ & 24 & $6.0(1.7)$ & 24 & $6.8(1.4)$ & 24 & $7.0(1.2)$ & 24 & $7.0(1.5)$ \\
\hline
\end{tabular}


cialization factors of the ComTRS (10). Last, the fifth factor ("Neuropsychomotor Speed") consisted of the time to complete the Immediate and Delayed Recall Bender.

\section{Discussion}

The results show that ethnic group, paternal occupation, hand preference and need for treatment (according to the teacher) had no effect on performance of the neuropsychological battery. Additionally, older chil- dren performed the Denckla Motor Persistence Task, the Right-Left Discrimination, the Immediate and Delayed Recall Bender, the Digit Span, the Color Span and the Human Figure Drawing Tests, but not the Garfield Motor Persistence Tests, better than younger children. Additionally, girls performed the Immediate and Delayed Recall Bender, the Visual-Visual subtest of the Color Span and the Human Figure Drawing better than boys. However, there were no differences between the peformance of boys and

Table 6 - Scores for the Harris Human Figure Drawing Test for boys and girls across age.

Data are reported as means with the standard deviation within parentheses. N, Number of children.

\begin{tabular}{|c|c|c|c|c|c|}
\hline \multirow{2}{*}{$\begin{array}{l}\text { Age } \\
\text { (years, months) }\end{array}$} & & \multicolumn{2}{|c|}{ Draw-a-Man } & \multicolumn{2}{|c|}{ Draw-a-Woman } \\
\hline & & Male & Female & Male & Female \\
\hline \multirow[t]{2}{*}{$5,0-5,5$} & $M(S D)$ & $10.7(4.7)$ & $9.4(3.9)$ & $11.3(4.5)$ & $8.8(3.7)$ \\
\hline & $\mathrm{N}$ & 12 & 10 & 12 & 10 \\
\hline \multirow[t]{2}{*}{$5,6-5,11$} & $\mathrm{M}(\mathrm{SD})$ & $10.0(2.6)$ & $14.6(4.6)$ & $10.9(3.3)$ & $14.4(4.1)$ \\
\hline & $\mathrm{N}$ & 12 & 14 & 12 & 14 \\
\hline \multirow[t]{2}{*}{$6,0-6,5$} & $M(S D)$ & $11.6(3.4)$ & $15.2(3.8)$ & $11.3(3.9)$ & $15.5(4.0)$ \\
\hline & $\mathrm{N}$ & 12 & 11 & 12 & 11 \\
\hline \multirow[t]{2}{*}{$6,6-6,11$} & $\mathrm{M}(\mathrm{SD})$ & $16.2(3.4)$ & $18.2(4.9)$ & $16.8(4.7)$ & $20.9(4.2)$ \\
\hline & $\mathrm{N}$ & 10 & 10 & 10 & 10 \\
\hline \multirow[t]{2}{*}{$7,0-7,5$} & $M(S D)$ & $16.5(5.8)$ & $19.3(5.3)$ & $16.0(4.7)$ & $21.1(7.1)$ \\
\hline & $\mathrm{N}$ & 12 & 12 & 12 & 12 \\
\hline \multirow[t]{2}{*}{$7,6-7,11$} & $\mathrm{M}(\mathrm{SD})$ & $16.1(4.7)$ & $17.9(4.4)$ & $15.1(3.9)$ & $19.7(4.3)$ \\
\hline & $\mathrm{N}$ & 11 & 11 & 11 & 11 \\
\hline \multirow[t]{2}{*}{$8,0-8,5$} & $M(S D)$ & $17.6(5.1)$ & $20.6(3.7)$ & $17.5(3.5)$ & $22.6(4.3)$ \\
\hline & $\mathrm{N}$ & 13 & 11 & 13 & 11 \\
\hline \multirow[t]{2}{*}{$8,6-8,11$} & $M(S D)$ & $17.1(5.5)$ & $19.1(5.3)$ & $19.1(7.5)$ & $19.1(5.4)$ \\
\hline & $\mathrm{N}$ & 11 & 11 & 11 & 11 \\
\hline \multirow[t]{2}{*}{$9,0-9,5$} & $M(S D)$ & $22.7(10.4)$ & $21.5(6.4)$ & $20.6(8.1)$ & $23.0(6.5)$ \\
\hline & $\mathrm{N}$ & 12 & 11 & 12 & 11 \\
\hline \multirow[t]{2}{*}{$9,6-9,11$} & $M(S D)$ & $24.8(6.0)$ & $23.3(6.4)$ & $25.5(6.5)$ & $24.5(6.9)$ \\
\hline & $\mathrm{N}$ & 10 & 10 & 10 & 10 \\
\hline \multirow[t]{2}{*}{$10,0-10,5$} & $\mathrm{M}(\mathrm{SD})$ & $21.5(6.8)$ & $22.4(3.5)$ & $20.1(5.0)$ & $24.6(5.5)$ \\
\hline & $\mathrm{N}$ & 11 & 13 & 11 & 13 \\
\hline \multirow[t]{2}{*}{$10,6-10,11$} & $M(S D)$ & $21.1(7.0)$ & $23.1(5.3)$ & $21.0(5.3)$ & $23.5(4.5)$ \\
\hline & $\mathrm{N}$ & 11 & 11 & 11 & 11 \\
\hline \multirow[t]{2}{*}{$11,0-11,5$} & $M(S D)$ & $26.3(10.4)$ & $26.5(6.6)$ & $27.2(10.7)$ & $30.9(8.5)$ \\
\hline & $\mathrm{N}$ & 11 & 10 & 11 & 10 \\
\hline \multirow[t]{2}{*}{$11,6-11,11$} & $M(S D)$ & $22.3(7.2)$ & $29.9(10.1)$ & $23.5(6.1)$ & $32.2(9.4)$ \\
\hline & $\mathrm{N}$ & 11 & 10 & 11 & 10 \\
\hline \multirow[t]{2}{*}{$12,0-12,11$} & $M(S D)$ & $28.2(8.4)$ & $30.9(8.5)$ & $27.4(8.5)$ & $34.3(10.7)$ \\
\hline & $\mathrm{N}$ & 10 & 11 & 10 & 11 \\
\hline \multirow[t]{2}{*}{$13,0-13,11$} & $M(S D)$ & $28.8(10.4)$ & $29.0(10.2)$ & $28.4(12.4)$ & $30.6(11.7)$ \\
\hline & $\mathrm{N}$ & 12 & 12 & 12 & 12 \\
\hline \multirow[t]{2}{*}{$14,0-15,11$} & $M(S D)$ & $33.3(13.4)$ & $28.1(5.7)$ & $31.7(10.1)$ & $30.2(7.8)$ \\
\hline & $\mathrm{N}$ & 11 & 13 & 11 & 13 \\
\hline
\end{tabular}


girls in Motor Persistence, Right-Left Discrimination, Digit Span and the remaining three subtests of the Color Span Test (Visual-Verbal, Verbal-Visual and Verbal-Verbal). Furthermore, the performance of nonachievers was equivalent to that of achievers in the Motor Persistence Tests, the Backward section of the Digit Span and the time to complete the Bender Tests, but was worse in the Right-Left Discrimination, the Immediate and Delayed Recall Bender, the Color Span subtests and the Human Figure Drawing Test. Comparison of our data to those gathered in the U.S. showed no differences between Brazilian and American children in the performance of the Motor Persistence and possibly the Backward Digit Span Tests. However, U.S. children outperform Brazilian children in the Right-Left Discrimination, the Forward Digit and the Color Span Tests, and the Human Figure Drawing. Lack of normative data in the U.S. precludes comparisons with Brazilian children in relation to the Immediate and Delayed Recall Bender. Factor analysis of the data for Motor Persistence and Right-Left Discrimination with the addition of the behavioral data and the performance of the Human Figure Drawing indicated the presence of five factors: $\mathrm{Hu}-$ man Body Representation, Hyperactivity-Inattention, Motor Persistence of the Legs, Anxiety-Negative Socialization, and OrbitoOrobuccal Motor Persistence. A similar factor analysis of the results in the Attention and Memory Tests demonstrated five factors: Attention-Memory, Visuospatial Memory, Hyperactivity-Inattention, AnxietyNegative Socialization, and Neuropsychomotor Speed.

The lack of effect of race on performance of the neuropsychological battery is in keeping with current controversies on the effect of racial differences on test performance. As discussed by Lezak (23), racial differences are confounded with socioeconomic differences, although there seems to be congruence in the subjacent abilities of cognitive tests between Caucasian and African Americans. As opposed to race, indices of socioeconomic status are commonly reported to have significant effects on neuropsychological test performance (e.g., 23). Therefore, the lack of effect of an index of socioeconomic status, i.e., paternal occupation, observed in the present study seems odd in view of the significance of socioeconomic variables for neuropsychological performance. For example, in a major review of the Human Figure Drawing Test, Scott (26) concluded that socioeconomic status had a more powerful effect on Human Figure Drawing than race, geographic location, or size of place of residence. It is possible that we could not find a significant effect for paternal occupation due to the relatively small sample size after removal of 114 children for whom parental occupation could not be ascertained.

As emphasized by Lezak (23), children's behavior is expected to change with age. Therefore, age effects on neuropsychological performance are to be expected, as reported in this study, and so age should be taken into account when using most of the normative data presented here, with the exception of Garfield's Motor Persistence Tests, which children performed at ceiling levels at all ages in the age range examined. Furthermore, it has been repeatedly shown that there is a differential rate in neurobehavioral development for boys and girls (23). Our data are consistent with this view insofar as we found that girls outperformed boys in several instruments of the neuropsychological battery used in the present study such as the Recall Bender and the Human Figure Drawing. Boys, however, did not outperform girls in any of the instruments of this battery. At best, they performed at the same level as girls. Interestingly, in contrast to the present report, Hutz and Antoniazzi (3) were unable to find gender differences in the performance of the Human Figure Drawing by Brazilian children. Differences in administration (one 
$v s$ three figures) and scoring procedures (Koppitz (24) vs Harris (9)) may account for the discrepancy between the two studies. Our results, however, are consistent with significant age, but not gender, effects reported for a battery of soft neurological signs, including standing on one leg and right-left discrimination, administered to Colombian children (27).

Our data indicate a discrepancy between clinical and criterion-related validity of the instruments included in the neuropsychological battery in the sense that the need for treatment as ascertained by teachers was without effect, while academic standing (achievers $v s$ nonachievers) had a significant effect on the performance of all tests of the neuropsychological battery with the exception of the Motor Persistence Tests and the Backward section of the Digit Span Test. The difference in performance between achievers and nonachievers is consistent with the available evidence in the sense that rightleft discrimination (4), and attention (e.g., 28) and memory (e.g., 13-15,28) difficulties may be related to achievement problems. The above discrepancy corroborates data published previously (22) and indicates that the neuropsychological battery used in the present study possesses criterion-related validity (i.e., the criterion of academic performance) but lacks clinical-related validity (i.e., teacher as a referral source). However, as discussed elsewhere (22), the apparent lack of clinical validity of the neuropsychological battery may be related to the fact that teachers involved in this study lack familiarity with behavioral rating scales, have limited clinical acumen or are more easily subjected to unspecified halo effects.

The dimensional structure analysis of the neuropsychological data suggests that motor persistence has two dimensions, one involving the legs and the other involving the orbicular muscles of the face and the glossal muscles of the oral cavity. Therefore, we can surmise the existence of corticospinal and corticobulbar subtypes of motor persistence, and the possibility that each subtype may be impaired differentially in the clinical setting. Furthermore, the factorial structure of the data suggests that Right-Left Discrimination is associated with the same dimension of test performance as the Human Figure Drawing, which may imply that it requires perceptuomotor or cognitive representational processes for its correct execution. The close association of Right-Left Discrimination and cognitive functioning has also been reported by other investigators (e.g., 29). Additionally, the finding that the error scores in the Immediate and Delayed Recall Bender were associated with the same factorial construct as the Digit Span and Color Span Tests indicates that these two Recall modalities of the Bender Test require attentional and working memory mechanisms for their execution. Moreover, the fact that performance in the Recall Bender modalities is also associated with the same dimension as the Human Figure Drawing Test implies that perceptuomotor or cognitive processes are required for their performance, in addition to attentional and working memory mechanisms. It is worthy to note that neuropsychomotor speed comprised an entirely independent factorial dimension, which is consistent with data reported elsewhere (22).

The dimensional analysis also demonstrated the close association of the ComTRS (10) factorial construct Hyperactivity-Conduct Problem, Inattention and Independent Functioning-Positive Socialization. Such close association is expected from data reported by our group (21) and others (e.g., 30,31). The observed association of the Anxiety and Negative Socialization dimensions of the ComTRS (10) should be expected inasmuch as anxious children often are withdrawn.

Brazilian children clearly performed worse than U.S. children in several instruments of the neuropsychological battery, and especially so in the Right-Left Discrimina- 
tion, Forward Digit Span and all four subtests of the Color Span Test. In a previous study, Brito and Santos (22) suggested that performance differences between Brazilian and U.S. children in the normal administration of the Bender Test probably reflect differences in academic learning time and deficiencies in school instruction techniques. We may advance the hypothesis that the same conclusion applies to the differences between the two groups of children demonstrated in the present study. In such a case, it is assumed that the cognitive requirements for the performance of the tests included in the neuropsychological battery used in the present study represent biologically secondary abilities in the terminology of Geary (32) or scientific concepts in the terminology of Vygotsky (33). In other words, the limited extent of formal academic instruction in Brazilian public schools may lead to underdevelopment of secondary abilities (e.g., pencil use, mental manipulation of numbers and verbal labeling of colors, to cite a few). It is probable, and one hopes, that due emphasis on school activities may reverse the effects of cultural and socioeconomic deprivation. Additionally, the reversal of these effects could have a significant and ameliorative impact on the bidirectional relationships between culture and biology as envisaged in a biocultural interaction model (34). Luria's (35) finding that illiterate individuals can make the transition from a concrete to an abstract thinking pattern after the acquisition of some formal school instruction can be considered consistent with the biocultural interaction model inasmuch as such a transition could lead to more sophisticated neuropsychological functioning and higher occupational status. In light of this evidence, Hunt's idea (36) that preschool enrichment could function as an antidote for cultural deprivation would appear to be pertinent. The importance of formal school instruction and enrichment could be evaluated by comparing the neuropsychological test performance of children in Brazilian public versus private schools. This work is in progress in our laboratory. In any event, the implications of our findings for the Brazilian public school system is clear. It remains to be seen whether our current political circumstances will allow the implementation of the critical and necessary changes in the public school sector.

\section{Acknowledgments}

The authors are indebted to Angela Guedes and Rubem Goulart (NPD-UFF) for assistance in data analysis and Raquel $P$. Silva for assistance during the preparation of the manuscript. The authors wish to thank the children who participated in the study and the staff of IEPIC (Instituto de Educação Prof. Ismael Coutinho).

\section{References}

1. Cunha JA (1993). PsicodiagnósticoRevisão. Artes Médicas, Porto Alegre, RS.

2. Kroeff $P(1988)$. Normas brasileiras para o teste de Bender. Psicologia: Reflexão e Crítica, 3: 10-17.

3. Hutz CS \& Antoniazzi AS (1995). O desenvolvimento do desenho da figura humana em crianças de 5 a 15 anos de idade: Normas para avaliação. Psicologia: Reflexão e Crítica, 8: 3-18.

4. Benton AL (1968). Right-left discrimination. Pediatric Clinics of North America,
15: $747-758$.

5. Denckla MB (1974). Development of motor coordination in normal children. Developmental Medicine and Child Neurology, 16: 729-741.

6. Garfield JC (1964). Motor impersistence in normal and brain-damaged children. Neurology, 14: 623-630.

7. Wechsler D (1974). Manual for the Wechsler Intelligence Scale For ChildrenRevised. The Psychological Corporation, New York.
8. Richman LC (1989). The Color Span Test Department of Pediatrics, University of lowa, lowa City, IA.

9. Harris DB (1963). Children's Drawings as Measures of Intellectual Maturity. Harcourt, Brace and World, New York.

10. Brito GNO \& Pinto RCA (1991). A Composite Teacher Rating Scale: Analysis in a sample of Brazilian children. Journal of Clinical and Experimental Neuropsychology, 13: 417-418.

11. Gardner RA (1979). The Objective Diag- 
nosis of Minimal Brain Dysfunction. Creative Therapeutics, Cresskill, NJ.

12. Denckla MB, Rudel RG, Chapman C \& Krieger J (1985). Motor proficiency in dyslexic children with and without attentional disorders. Archives of Neurology, 42: 228231.

13. Lindgren SD \& Richman LC (1984). Immediate memory functions of verbally deficient reading-disabled children. Journal of Learning Disabilities, 17: 222-225.

14. Lindgren SD, Richman LC \& Eliason MJ (1986). Memory processes in reading disability subtypes. Developmental Neuropsychology, 2: 173-181.

15. Wood KM, Richman LC \& Eliason MJ (1986). Immediate memory functions in reading disability subtypes. Brain and Language, 36: 181-192.

16. Brito GNO, Brito LSO \& Paumgartten FJR (1985). Effect of age on handedness in Brazilian adults is sex-dependent. Perceptual and Motor Skills, 61: 829-830.

17. Brito GNO (1987). The Conners Abbreviated Teacher Rating Scale: Development of norms in Brazil. Journal of Abnormal Child Psychology, 15: 511-518.

18. Brito GNO (1987). The Conners Abbreviated Teacher Rating Scale: A factor analysis study in Brazil. Brazilian Journal of Medical and Biological Research, 20: 553556.

19. Brito GNO, Brito LSO, Paumgartten FJR \& Lins MFC (1989). Lateral preferences in Brazilian adults: An analysis with the
Edinburgh Inventory. Cortex, 25: 403-416.

20. Brito GNO, Lins MFC, Paumgartten FJR \& Brito LSO (1992). Hand preference in 4to 7-year old children: An analysis with the Edinburgh Inventory in Brazil. Developmental Neuropsychology, 8: 59-68.

21. Brito GNO, Pinto RCA \& Lins MFC (1995). A behavioral assessment scale for attention deficit disorder in Brazilian children based on DSM-IIIR criteria. Journal of Abnormal Child Psychology, 23: 509-520.

22. Brito GNO \& Santos TR (1996). The Bender Gestalt test for 5- to 15-year old Brazilian children: Norms and validity. Brazilian Journal of Medical and Biological Research, 29: 1513-1518.

23. Lezak MD (1995). Neuropsychological Assessment. 3rd edn. Oxford University Press, New York.

24. Koppitz EM (1975). The Bender Gestalt Test for Young Children. Vol. II. Research and Application. Grune \& Stratton, New York.

25. SAS Institute (1982). Statistics. SAS Institute, Cary, NC.

26. Scott LH (1981). Measuring intelligence with the Goodenough-Harris Drawing Test. Psychological Bulletin, 89: 483-505.

27. Ardila A \& Rosselli M (1997). Soft neurological signs in children: A normative study. Developmental Neuropsychology, 12: 181-200.

28. Mariani MA \& Barkley RA (1997). Neuropsychological and academic functioning in preschool boys with attention deficit hyperactivity disorder. Developmental Neuropsychology, 13: 111-129.

29. Benton AL, Hamsher K de S, Varney NR \& Spreen O (1983). Contributions to Neuropsychological Assessment: A Clinical Manual. Oxford University Press, Oxford, New York.

30. Healey JM, Newcorn JH, Halperin J, Wolf LE, Pascualvaca DM, Schmeidler J \& O'Brien JD (1993). The factor structure of ADHD items in DSM-III-R: Internal consistency and external validation. Journal of Abnormal Child Psychology, 21: 441453.

31. DuPaul GJ (1991). Parent and teacher ratings of ADHD symptoms: Psychometric properties in a community-based sample. Journal of Clinical Child Psychology, 20: 245-253.

32. Geary DC (1996). Sexual selection and sex differences in mathematical abilities. Behavioral and Brain Sciences, 19: 229284.

33. Vygotsky L (1986). Thought and Language. MIT Press, Cambridge.

34. Schell LM (1997). Culture as a stressor: A revised model of biocultural interaction. American Journal of Physical Anthropology, 102: 67-77.

35. Luria AR (1979). The Making of Mind. Harvard University Press, Cambridge.

36. Hunt JM (1964). The psychological basis for using pre-school enrichment as an antidote for cultural deprivation. MerrillPalmer Quarterly, 10: 209-247. 